\title{
On the Reform of Educational System from the Influence of Perceived Self-efficacy on Learning Motivation
}

\author{
Lingling Zhang \\ Department of Automation Engineering, Engineering and Technical College of Chengdu, University \\ of Technology, Leshan, Sichuan 614000, P.R. China
}

515851377@qq.com

Keywords: Perceived self-efficacy; Learning motivation; Diversified education system reform

\begin{abstract}
Perceived self-efficacy determines the individual's attitude in the development process when facing with new tasks, whether it is treated as a challenge or as a difficulty to avoid, and the effort degree of the individual in the activity, so it has profound impact on the whole process of learning and learning effects, but also determines the level of individual achievement. The current single education system with the college entrance examination as a baton is not conducive to the cultivation of high level of perceived self-efficacy for the majority of students, and cannot take student as the main bod or provide appropriate education for each student. It is suggested to implement the reform of diversified education system, which is based on people oriented and individualized teaching.

The perceived self-efficacy is a core concept proposed by American psychologist Bandura in the theory of social learning. It refers to the level at which the individual can perform the activity before performing a certain action and have what kind of conviction, judgment, or individual self-perception (Bandura, 1994). [1]

In general, when people face different circumstances, the individual choose the environment that is considered can be effectively coped with, and avoid the environment cannot be controlled. The level of perceived self-efficacy determines the attitude of the individual in the development process when facing with new tasks, whether it is treated as a challenge or as a difficulty to avoid. Thus, when the individual selects the target, the stronger perceived self-efficacy, the more challenging individual's set goal, and the higher the level of achievement. The degree of challenge of the target constitutes a factor in the individual's dynamic mental process. It not only stimulates the individual's motivation level, but also determines the individual's involvement degree in the activity and thus determines the actual achievement of his activity.

In addition, perceived self-efficacy also affects the individual's efforts in the activity, as well as the individual's endurance for the activity in the event of difficulties, setbacks and failure. Especially for those challenging activities or tasks, this endurance is the essential condition to ensure success of the activities. Strong perceived self-efficacy encourages individuals to spend more effort and perseverance in their activities until they reach the goal of activity. And people with low perceived self-efficacy will begin to doubt whether they can complete the activities well in the event of meeting the initial difficulties or setbacks, and thus are satisfied with the mediocre achievements, and even give up their own efforts to abandon their efforts, willing to become losers.
\end{abstract}

\section{The Influence of Perceived Self-efficacy on Learning Motivation System}

The author has constructed an effective learning system model in The Analysis of Effective Learning Motivation System Based on Growth Management [2] and explored the dynamic mechanism of the whole effective learning system in the paper. We found that learners' perceived self-efficacy had a far-reaching impact on the whole learning process and learning outcomes throughout the learning dynamics system model.

Impact on Motivation Generation. Motivation is caused by the need, and the human's needs have different aspects and levels. Perceived self-efficacy plays an important role in the process of motivation generation. Those motivating factors with low perceived self-efficacy are often hard to 
become real motivation. For example, the academic performance has always been in the bottom of the students, it is difficult to generate the motivation that make their achievements in the forefront with their own efforts; the ones think their own hands-on ability is poor will rarely take the initiative to generate the interest for driving cars, machine tools and other related work; the perceived self-efficacy of the addicts in online games is significantly higher than the perceived self-efficacy they experience in other social interactions, including learning.

The Impact of Internal Motivation into Learning Goals and Learning Attitude. According to Bandura's study, human behavior mostly accepts the goal-setting and forethought adjustments. In the process of transforming a variety of generated learning motivations into learning goals, people who have established a higher perceived self-efficacy in previous personal learning experiences tend to set goals that are challenging and transcendent. On the contrary, the people with low perceived self-efficacy tend to set the fuzzy target with low difficulty, psychological protection, and even avoid the establishment of clear learning objectives.

The default learning goal will form a basic psychological situation before the formal action, that is, learning attitude. Learning attitude consists of three psychological components: cognition, emotion and intention. The formation of attitudes begins with the learners' forethought of the forthcoming actions. One expression form of forethought is the imaginal realization of activities in imagination, that is, forming a vivid, distinct imaginal characterization for the activity scene or scenarios of actions to be implemented. If an individual is convinced of his or her own performance, he will tend to imagine a successful scene and experience subtle changes in the physical state associated with the activity in order to provide support and guidance for the physical execution of the activity. On the contrary, those who doubt their own performance imagine more about the failure scene, and often take the difficulties as more serious and more terrible than the actual situation. Such perceived coping inefficacy perceived or implied by the forethought is often accompanied by a strong sense of subjective pain, feeling the danger of environment, and experiencing a strong stress response and anxiety, and taking negative or withdrawal behavior or defensive behavior, which greatly limits the individual initiative to play.

Because of the important psychological effect of positive attitude or negative negation from learning attitude and learning situation, the learning goal presupposed by the subject will not be transformed into really effective learning behavior without the affirmed and positive psychological situation after forethought.

Impact on the Level of Self-Learning Management. In view of the high degree of intrinsic nature of learning behavior, learning self-management is the key to achieve the corresponding behavioral performance. The self-management of learning includes the main contents of setting appropriate goals, organizing corresponding resources, adopting appropriate strategies, learning incentives and the control of learning actions. The impact of perceived self-efficacy on self-management can be divided into two categories:

Firstly, it's the perceived self-efficacy on learning plan and organization. Goals, resources and strategies have diversity and require individuals to understand, develop, select, and execute from many possibilities. In the process of choosing a goal, a resource, and a strategy, the experience of individual's previous cognition, choice, and giving up is a sense of pleasure that people has repeatedly experienced the recognition and praise of others and the self, or a sense of psychological pain that people have experienced constantly frustrating and blaming, forming the individual's perceived self-efficacy for cognitive behavior, and it will control the follow-up behavior of individuals to a large extent.

Secondly, the perceived self-efficacy of process management: including two perceived self-efficacy: behavioral control and affordability. Many students who learn from the failed experience in the past have such experience: they know that a certain behavior can improve academic performance, and have once tried to do so, but ultimately failed to control their own behavior, and chose to give up their own the right thing in their mind. The process of failing to control their behaviors is often accompanied by the painful process of suffering against hard work. Because learning itself is the process of learners' growth, it is a process from immaturity to maturity 
(including from unknown to known, from incapable to capable, from spicy to skilled, from confused to clear). This process is often compared to the transformation from silkworm to butterflies, so it will inevitably need a lot of mental and physical effort, often going through a process of great pain. If there is no support for the perceived self-efficacy of learning process management, and the success of learning is impossible.

In particular, when the process of painful experience is accompanied with the eventual failure, learners will have flinty negative attitude about being able to manage their own learning behavior and break through the difficulties and eventually achieve the success of learning. Their perceived self-efficacy level is decreased to a very low level, so we can observe their negative learning, giving up or even boycott.

\section{The Institutional Problems Faced by Cultivating Perceived Self-Efficacy}

Since learning perceived self-efficacy plays a very important role in the process of learning motivation, then a very important purpose of education is to carefully follow and cultivate learners' perceived self-efficacy, which is far more important than specific knowledge and skills training. We believe that inappropriate learning education (including contents and methods), if the result is to continue to bring learners to reduce the perceived self-efficacy, then this education is a failure of education. The great negative impact it brings to the educatee deviates from the original education intention, in a sense, this failed education is likely to destroy a person.

Human values in modern society are diversified, and the potential of different individuals is diversified. The biggest problem with our real education lies in the fact that for our diverse social needs and personal potential, our education almost has a single channel and a model. Taking college entrance examination as a baton, all secondary education is for college entrance examination. And the college entrance examination results determine the situation of secondary education, thus determines the direction of primary school education and even early childhood education. The education department has repeatedly asked to reduce the burden of students with administrative orders, prohibited taking kindergarten as primary school, but with little success. The key lies in the practical needs of the future study.

In such a unified education system, the standardized learning subjects offered by the school become the only recognized learning contents. And the standardized assessment results become the only measure of learning ability. The students cannot adapt to standardized educational system will inevitably lead to learning backward and become poor students, and low learning perceived self-efficacy experience will continue until the end of all school learning period. The result of long-term repetition of the detailed individual perceived self-efficacy in completing the specific task is to form the general sense of perceived self-efficacy[3] of the individual. Therefore, in our existing education system, learning losers will eventually get out of school with a very low general perceived self-efficacy, going to the community. According to statistics, in recent years, the annual admission rate of undergraduate college entrance examination in all provinces averages about $50 \%$, while the students under secondary college enter into the next stage of life with varying degrees of failure sense. In the learning ability measure standard of college entrance examination-oriented, more than half of the students cannot adapt well to the existing education system. College entrance examination failure only takes up a very small part. Before such failure, most of them have gone through 12 Year of learning failure, and in the follow-up education and even life experience, this learning frustration will continue to have an impact.

\section{The Implementation of Diversified Education System to Cultivate Students' Perceived Self-Efficacy}

Perceived self-efficacy is not immutable. In many cases, it is a variable that may change with some success or failure experience, and it may not be exactly the same as the actual situation of the individual's ability. As a kind of social function, its essence is growth management of the educatee. The ultimate goal is to make the educatee be able to survive and develop in the society on the basis 
of his/her own efforts, and become a person having positive significance to society and himself. Learning itself is not an end in itself, but it is a kind of process experience making people grow from an immature state to mature state. Education should be people-oriented, that is, to recognize and respect the individual's differences, individualization, so that each educatee gets the appropriate education.

National Long-Term Education Reform and Development Plan (2010-2020) clearly puts forward: "to take students as the mainstay, teacher-led, give full play to the initiative of students, to take promoting healthy growth of students as the starting point and objective of all the work of the school. And focus on each student, promote each student grow initiatively and lively, respect the law of education and physical and mental development of students, to provide appropriate education for each student.

The outline of the Plan is very clear, but the existing single education system is unable to make each student develop actively and lively, because it cannot take the student as the main body, nor adapt to the physical and mental development learning law of students. Therefore, the author believes that to achieve the requirements of Plan, the education system should be diversified to meet the needs of social talent and educatees' diversification.

The key of the diversification of the educational system lies in the diversification of evaluation system. Over the years, our basic education system has been based on the development of students' multidisciplinary and complete development. The mark is that students must take into account every course offered by the school, and the school will rank the students with the total score. Thus the students are tagged as good student and poor student. This evaluation system is in line with the requirements of the forward college entrance examination. But because a considerable number of students are partial to certain subjects, in some areas, they have outstanding or relatively good performance, and in some other aspects, they have learning difficulties. These difficulties for some students can be overcome by hard learning, but for some students, they have become insurmountable obstacles. At the same time, for some students who have special talents in a particular field, the requirements of unified and comprehensive development can be a disaster because they cannot use their energy to develop the specialty, but are deeply troubled by the subjects they are not good at and become dejected.

In fact, this may be our misinterpretation of "all-round development". It refers to the educatees' moral and intellectual aspects cannot be neglected, rather than requesting and dividing the students with unified general comprehensive results. The education system with college entrance examination as the baton just alienate moral education (take the performance of political class as a measure, to make moral education into a test of students' rote of political textbooks), missing the students' education of physical education and aesthetic education (to make students focus on the subjects of examination, schools feel free to squeeze the students' physical education, encourage students to exercise with books, and even limit students to participate in physical exercise, and aesthetic education is compressed in the greatest degree), emphasizing the academic performance unitarily. Is this the "all-round development" we are pursuing?

The implementation of diversified evaluation system should be free from the current united curriculum. The credit system should be conducted from the basic education, allowing students to choose their interested courses. The school forms a set of test system for students' academic ability to test the students' interest and potential at different stages. The teacher guides the students to choose the curriculum system which not only meets the actual situation of students but also meets the established educational and teaching objectives. Thus, it is really a student-oriented education that every student can choose to develop their own interests, develop their own hobbies and manage their own studies from an early age with initiative. The independent choice is conducive to the form a positive attitude of learning and the responsibility for themselves, so that there will be more adequate internal learning motivation, which can really pay for learning efforts, to obtain learning progress, thus to achieve gradual increase of perceived self-efficacy in learning.

In the implementation of diversified evaluation system in basic education, the key lies in the college entrance examination system. Under the current college entrance examination system, the 
diversification evaluation system will be regarded as unrealistic talk. But in fact, for the stage of higher education, the current sub-admission method with college entrance examination score still ignores the students' real academic ability, students may be not suited for the majors they are admitted. Those partial students who have special talents in some areas do not have the opportunity for further education. The standardized curriculum system stifles the students' original ability to make talented students unable to stand out. Therefore, it's the problem that education management departments need to seriously think about how to rationalize the reform of college entrance examination system so that it is really conducive to all kinds of talent.

\section{References}

[1] S. C. Gao: Chinese Journal of Psychology and Education, (2000) No.1, p 60

[2] L. L. Zhang, H. B. Ma: Teaching and Management, Vol. 30(2014) No.10, p 15

[3] C. Q. Lu: Journal of Psychology, Vol. 36 (2004) 5, p586 